\title{
EVALUASI KONDISI PERKERASAN LENTUR DENGAN MENGGUNAKAN METODE Pavement Condition Index (PCI) PADA RUAS JALAN SAKO BARU KECAMATAN SAKO PALEMBANG
}

\author{
Asrullah \\ Dosen Tetap Program Studi Teknik Sipil \\ Fakultas Teknik Universitas Palembang \\ email : asrull66@yahoo.co.id
}

\begin{abstract}
Abstrak
Jalan merupakan prasarana transportasi darat yang dibutuhkan manusia untuk dapat melakukan pergerakan dari suatu lokasi ke lokasi lainnya dalam rangka pemenuhan kebutuhan. Namun, jalan yang terbebani oleh volume lalu lintas yang berulang-ulang akan menyebabkan terjadinya penurunan kualitas jalan. Ruas jalan Sako Baru termasuk dalam kategori jalan arteri sekunder. Secara visual di sepanjang jalan ini banyak dijumpai permukaan jalan dalam kondisi rusak. kerusakan tersebut cukup jelas dibedakan bila dibandingkan dengan seksi jalan yang tidak rusak. Kondisi jalan yang rusak apabila dibiarkan terus menerus akan mengalami kerusakan semakin parah seiring berjalannya waktu, selain itu juga membahayakan keselamatan pengguna jalan. Oleh karena itu, perlu dilakukan perbaikan untuk mencegah kerusakan jalan yang semakin parah. Dalam penelitian ini, digunakan metode $P C I$ untuk menghitung tingkat pelayanan jalan secara visual. Hasil penelitian menunjukkan bahwa kerusakan jalan didominasi oleh jenis kerusakan adalah alligator cracking sebesar 2,591\%, depressions sebesar 0,267\%, edge cracking sebesar 0,019\%, shoulder drop off sebesar $0,017 \%$, patching \& utillity cut patch sebesar $1,346 \%$, potholes sebesar $0,189 \%$, dan weathering/ravelling sebesar $0,377 \%$. dengan nilai kinerja perkerasan terendah berada pada seksi 14 sebesar 18 (very poor) sedangkan nilai kinerja perkerasan tertinggi berada pada seksi 15 sebesar 79 (very good).
\end{abstract}

Kata kunci : Kerusakan jalan, Pavement Condition Index (PCI)

\section{LATAR BELAKANG}

Perencanaan suatu jalan yang baik merupakan hal penting yang diperlukan untuk mewujudkan konstruksi jalan yang dapat mendukung kelancaran dan kenyamanan bagi para pengguna jalan. Pembangunan jalan yang baik, diharapkan mampu menyalurkan beban kendaraan yang dilaluinya ke tanah dasar tanpa mengalami kerusakan-kerusakan sesuai dengan umur rencana dan masa kelayakannya. Jalan merupakan prasarana transportasi darat yang dibutuhkan manusia untuk dapat melakukan pergerakan dari suatu lokasi ke lokasi lainnya dalam rangka pemenuhan kebutuhan. Namun, jalan yang terbebani oleh volume lalu lintas yang berulang-ulang akan menyebabkan terjadinya penurunan kualitas jalan.

Setiap tahunnya pemerintah mengeluarkan dana untuk melakukan pemeliharaan terhadap ruas-ruas jalan di seluruh Indonesia, baik itu pemeliharaan rutin maupun pemeliharaan berkala yang seharusnya tidak perlu dilakukan akibat terjadinya kerusakan dini pada ruas jalan tersebut. Dari sekian ruas jalan yang ada di kota Palembang salah satunya adalah ruas jalan Sako Baru, yang merupakan jalan arteri sekunder dan keberadaannya sangat penting, karena pada jalur ini merupakan penghubung utama masyarakat di kelurahan Sako Baru Kecamatan Sako kota Palembang dalam moda trasportasi darat.

Ruas jalan tersebut sudah direncanakan sesuai dengan standar desain yang ditetapkan oleh instansi terkait. Akan tetapi dengan berubahnya komposisi beban lalu lintas terjadi kerusakan-kerusakan dini yang seharusnya tidak perlu terjadi, mengingat umur rencananya belum terlampaui. Kerusakankerusakan yang terjadi saat ini diantaranya retak blok, lubang, retak memanjang dan melintang, retak kulit buaya, retak pinggir, tambalan dan tambalan galian utilitas. Penilaian kondisi jalan perlu dilakukan secara periodik baik struktural maupun nonstruktural. Agar jalan dapat tetap mengakomodasi kebutuhan pergerakan dengan 
tingkat layanan tertentu maka perlu dilakukan suatu usaha untuk menjaga kualitas layanan jalan, dimana salah satu usaha tersebut adalah mengevaluasi kondisi permukaan jalan.

Berdasarkan keadaan tersebut di atas, maka diperlukan penelitian untuk mengevaluasi kondisi perkerasan jalan sesuai dengan jenis dan tingkat kerusakan, ruas jalan yang akan menjadi objek dalam penelitian adalah ruas jalan Sako Baru dengan panjang keseluruhan 1.200 meter dan untuk objek penelitian sepanjang 960 meter. Supaya jalan dapat tetap mengakomodasi kebutuhan pergerakan dengan tingkat layanan tertentu, maka perlu dilakukan suatu usaha untuk menjaga kualitas layanan jalan, di mana salah satu usaha adalah dengan melakukan jalan. penilaia terhadap kondisi eksisting

Nilai kondisi jalan ini nantinya dijadikan acuan untuk menentukan jenis penanganan yang harus dilakukan, apakah itu peningkatan pemeliharaan berkala,

pemeliharaan rutin atau dengan overlay. Ada beberapa metode pendekatan yang dapat digunakan dalam melakukan penilaian kondisi jalan, diantaranya adalah dengan metode Pavement Condition Index (PCI) [1].

\section{TINJAUAN PUSTAKA}

\subsection{Jenis Perkerasan Jalan}

Perkerasan berfungsi melindungi tanah dasar dan lapisan-lapisan pembentuk perkerasan supaya tidak mengalami tegangan dan regangan yang berlebihan oleh akibat beban lalu lintas. Pertimbangan tipe perkerasan yang dipilih terkait dengan dana pembangunan yang tersedia, biaya pemeliharaan, serta kecepatan pembangunan agar lalu lintas tidak terlalu lama terganggu oleh pelaksanaan proyek. Perkerasan dapat diklasifikasikan menjadi tiga yaitu: perkerasan lentur, perkerasan kaku, dan perkerasan komposit [2].

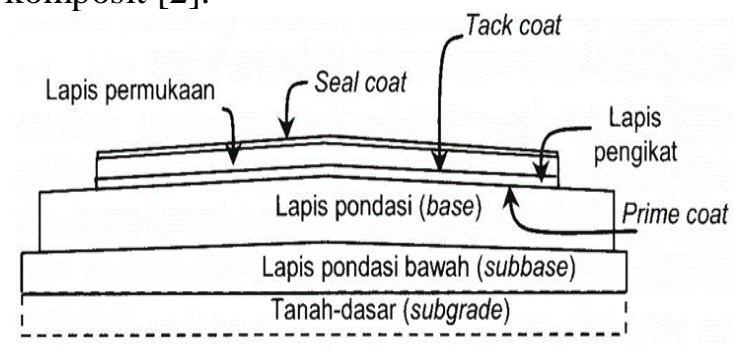

Gambar 1. Perkerasan Lentur

\subsection{Jenis-Jenis Kerusakan Perkerasan Jalan}

Jenis kerusakan perkerasan lentur (aspal), umumnya dapat diklasifikasikan sebagai berikut [2] :

1. Perubahan bentuk (deformation)

2. Retak (cracks)

3. Kerusakan tepi (edge defect)

4. Cacat permukaan (surface texture deficienci)

5. Lubang (pot holes)

6. Tambalan (patches)

\subsection{Metode Pavement Condition Index}

Metode Pavement Condition Index (PCI) adalah sistem penilaian kondisi perkerasan jalan berdasarkan jenis, tingkat kerusakan, sehingga dapat digunakan sebagai acuan dalam usaha pemeliharaan dan perbaikan. Metode PCI memberikan informasi kondisi perkerasan hanya pada saat survei dilakukan, tapi tidak dapat memberikan gambaran prediksi di masa datang. Namun demikian, dengan melakukan survei kondisi secara periodik, informasi kondisi perkerasan dapat berguna untuk prediksi kinerja di masa datang, selain juga dapat digunakan sebagai masukanpengukuran yang lebih detail [2]

Kondisi perkerasan jalan berdasarkan jenis, tingkat kerusakan yang terjadi dan dapat digunakan sebagai acuan dalam usaha pemeliharaan. Nilai PCI ini memiliki rentang 0 (nol) sampai 100 (seratus) dengan kriteria sempurna (excellent), sangat bagus (very good) , baik (good), sedang (fair), jelek (poor), sangat jelek (very poor), dan gagal (failed). Pembagian nilai kondisi perkerasan yang disarankan oleh FAA (1982) dan Shahin (1994) ditunjukan dalam Tabel 1 [3].

Tabel 1. Nilai PCI dan Kondisi

\begin{tabular}{cl}
\hline Nilai PCI & \multicolumn{1}{c}{ Kondisi } \\
\hline $0-10$ & Gagal (failed) \\
$11-25$ & Sangat buruk (very pool) \\
$26-40$ & Buruk (poor) \\
$41-55$ & Sedang (fair) \\
$56-70$ & Baik (good) \\
$71-85$ & Sangat baik (very good) \\
$88-100$ & Sempurna (exellent) \\
\hline
\end{tabular}

\subsection{Hitungan $P C I$}

Dalam perhitungan $P C I$, terdapat istilah-istilah sebagai berikut ini [4] : 1. Nilai pengurang (Deduct Value, DV) 
Nilai pengurang (deduct value) adalah suatu nilai pengurang untuk setiap jenis kerusakan yang diperoleh dari kurva hubungan kerapatan (density) dan tingkat keparahan (severity level) kerusakan. Nilai pengurang pada grafik dapat dilihat pada Gambar 2. berikut.

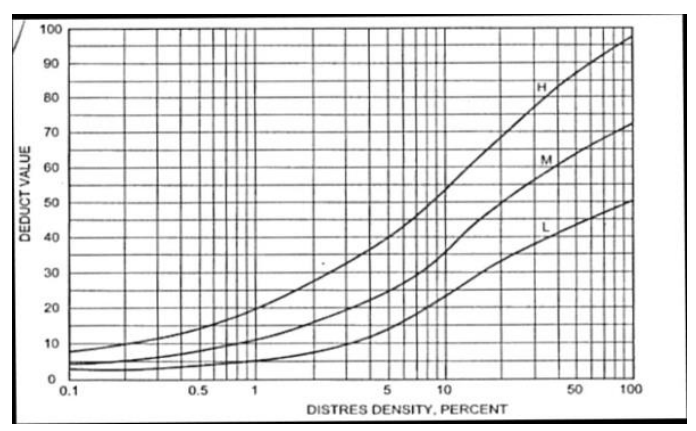

Gambar 2 Nilai Pengurang (Deduct Value)

\section{Kerapatan (density)}

Kerapatan (density) adalah nilai adalah persentase luas atau panjang total dari satu jenis kerusakan terhadap luas atau panjang total bagian jalan yang diukur, bias dalam sq.ft atau $\mathrm{m}^{2}$, atau dalam feet atau meter. Dengan demikian, kerapatan kerusakan dapat dinyatakan oleh persamaan:

$$
\text { Kerapatan }(\text { density })(\%)=\frac{A d}{A s} \mathrm{X} 100
$$

Atau

$$
\text { Kerapatan }(\text { density })(\%)=\frac{L d}{A s} \times 100
$$

\section{Dengan:}

$\mathrm{Ad}=$ luas total dari satu jenis perkerasan untuk setiap tingkat keparahan kerusakan (sq.ft atau $\mathrm{m}^{2}$ )

$\mathrm{A}_{\mathrm{S}}=$ luas total unit sampel (sq.ft atau $\mathrm{m}^{2}$ )

$\mathrm{L}_{\mathrm{d}}=$ panjang total jenis kerusakan untuk tiap tingkat keparahan kerusakan

\section{Nilai pengurang total (Total Deduct Value, TDV)}

Nilai pengurang total atau TDV adalah jumlah total dari nilai pengurang (deduct value) pada masing-masing unit sampel.

\section{Nilai-pengurang terkoreksi (Corrected Deduct Value)}

Nilai pengurang terkoreksi atau CDV diperoleh dari kurva hubungan antara nilaipengurangan total (TDV) dan nilai pengurangan $(D V)$ dengan memilih kurva yang sesuai. Jika nilai $C D V$ yang diperoleh lebih kecil dari pengurangan tertinggi , maka $C D V$ yang digunakan adalah nilai pengurangan individu yang tertinggi.



\section{Gambar 3. Koreksi Kurva untuk Jalan dengan Permukaan Aspal}

\section{Nilai $P C I$}

Setelah $C D V$ diperoleh, maka $P C I$ untuk setiap unit sampel dihitung dengan menggunakan persamaan:

$$
P C L_{S}=100-\mathrm{CDV}
$$

Dengan :

$P C L s=P C I$ untuk setiap unit sampel atau unit penelitian, $C D V$ adalah $C D V$ dari setiap unit sampel.

Nilai PCI perkerasan secara keseluruhan pada ruas jalan tertentu adalah:

$$
P C I_{f}=\sum P C L s / N
$$

\section{Dengan :}

PCI $r=$ nilai PCI rata-rata dari seluruh area penelitian

$P C L s$ = niali PCI untuk setiap unit sampel $N \quad=$ Jumlah unit sampel

\section{Unit Sampel}

Unit Sample adalah bagian atau seksi dari suatu perkerasan yang di definisikan hanya untuk keperluan pemeriksaan. Untuk jalan dengan perkerasan aspal (termaksuk aspal di atas perkerasan beton) dan jalan tanpa perkerasan, unit sampel di definisikan sebagai luasan sekitar $762 \pm 305 \quad \mathrm{~m}^{2}$ $(2500 \pm 1000$ sq.ft) [5] 


\subsection{Kondisi Existing Jalan Sako Baru}

Dari hasil survey yang dilakukan pada ruas jalan Sako Baru sepanjang 1.200 meter maka terdapat kerusakan berat sepanjang 960 meter yaitu dari stasiun $0+000$ s.d stasiun $0+360$ dan stasiun $0+420$ s.d stasiun $1+020$ dengan kerusakan meliputi, retak buaya sedang, retak buaya ringan, retak buaya berat, amblas sedang, tambalan sedang dan butiran lepas sedang. Untuk gambaran kondisi tersebut dapat dilihat dari dokumentasi lapangan seperti berikut.

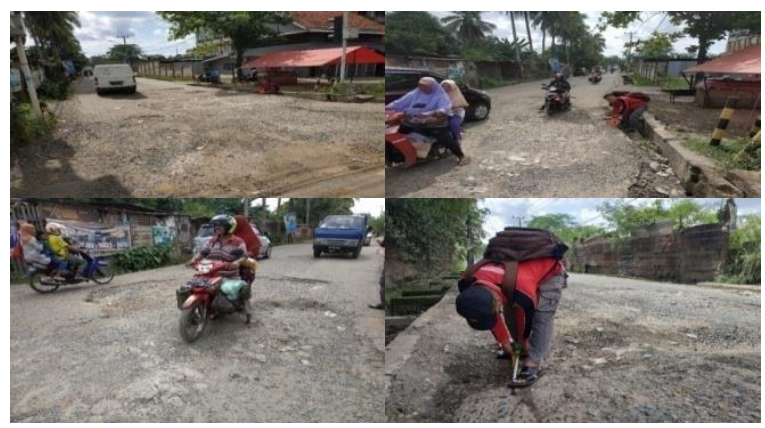

Gambar 4. Kondisi Existing Ruas Jalan Sako Baru di beberapa STA

\section{METODE PENELITIAN}

\subsection{Lokasi Penelitian}

Lokasi penelitian ini dilaksanakan pada ruas jalan Sako Baru kecamatan Sako kota Palembang sepanjang 1.200 meter yang dilakukan dalam penelitian ini sepanjang 960 meter dibagi menjadi 2 segmen yang terdiri dari segmen I yaitu $360 \mathrm{~m}$ STA $0+000$ s/d 0+360 dan segmen II $600 \mathrm{~m}$ (sta.0+420 s/d 1+020), dan lebar jalan $=5,7 \mathrm{~m}$ atau $18,7 \mathrm{ft}$. Perhitungan luas sampel dipakai $342 \mathrm{~m}^{2}$ dengan panjang $60 \mathrm{~m} \quad(196,8 \mathrm{ft})$ tiap segmen dan lebar $5,7 \mathrm{~m}(18,7 \mathrm{ft})$ sehingga terdapat 16 total seksi.

\subsection{Penentuan unit sampel yang disurvei}

Tujuan dari penentuan sampel ini adalah untuk mengevaluasi bagian perkerasan spesifik pada tingkat-proyek. Jaringan jalan yang dibagi ke dalam beberapa unit sampel, kemudian dipetakan jaringan jalan untuk dibagi ke dalam beberapa unit sampel.

\subsection{Langkah-Langkah Penelitian Metode PCI}

Berikut merupakan uraian langkah langkah penelitian metode $P C I$ yang meliputi alat-alat yang dibutuhkan, dan pengambilan data di lapangan.

\section{Alat yang Digunakan}

Peralatan yang digunakan dalam penelitian $P C I$ adalah sebagai berikut

- rol meter/hand odometer

- mistar untuk mengukur kedalaman kerusakan jalan,

- kamera untuk dokumentasi, dan

- formulir data survei kondisi jalan (manual kerusakan $P C I)$.

2. Langkah-Langkah Pengambilan Data di Lapangan

Berikut adalah langkah-langkah pengujian $P C I$ yaitu:

- Memeriksa satu unit sampel dengan mengukur tipe kerusakan dan tingkat kerusakannya. Satu lembar formulir data digunakan untuk satu unit sampel. Perkerasan dibagi untuk setiap jarak $60 \mathrm{~m}$ dan lebar 5,7 m dengan luasan tiap segmen $342 \mathrm{~m}^{2}$,

- Jalan Sako Baru objek penelitian dengan panjang 960 meter dibagi menjadi 16 seksi. Untuk pembagian segmen jalan dapat dilihat pada Gambar 4 berikut

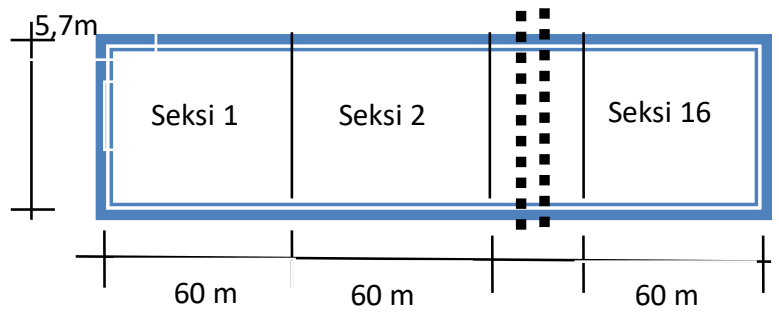

\section{Gambar 5. Pembagian Seksi Ruas Jalan Lokasi Penelitian}

\section{HASIL DAN PEMBAHASAN} 4.1. Nilai $P C I$

Dari hasil perhitungan maka didapat nilai $P C I$ seperti pada tabel 2 berikut ini :

\begin{tabular}{cccc}
\hline Seksi & STA & $\begin{array}{c}\text { Nilai } \\
\text { PCI }\end{array}$ & Rating \\
\hline 1 & $0+000$ s/d $0+060$ & 36 & Poor \\
2 & $0+060$ s/d $0+120$ & 61 & Good \\
3 & $0+120$ s/d $0+180$ & 42 & Fair \\
4 & $0+180$ s/d $0+240$ & 70 & Good \\
5 & $0+240$ s/d $0+300$ & 49 & Fair \\
6 & $0+300$ s/d $0+360$ & 46 & Fair \\
\hline Nilai rata-rata PCI Segmen I & $\mathbf{5 0 , 6}$ & Fair \\
\hline
\end{tabular}




\begin{tabular}{cccc}
\hline 7 & $0+420 \mathrm{~s} / \mathrm{d} 0+480$ & 60 & Good \\
8 & $0+480 \mathrm{~s} / \mathrm{d} 0+540$ & 51 & Fair \\
9 & $0+540 \mathrm{~s} / \mathrm{d} 0+600$ & 45 & Fair \\
10 & $0+600 \mathrm{~s} / \mathrm{d} 0+660$ & 34 & Poor \\
11 & $0+660 \mathrm{~s} / \mathrm{d} 0+720$ & 44 & Fair \\
12 & $0+720 \mathrm{~s} / \mathrm{d} 0+780$ & 30 & Poor \\
13 & $0+780 \mathrm{~s} / \mathrm{d} 0+840$ & 56 & Good \\
14 & $0+840 \mathrm{~s} / \mathrm{d} 0+900$ & 18 & Very Poor \\
15 & $0+900 \mathrm{~s} / \mathrm{d} 0+960$ & 79 & Very Good \\
16 & $0+960 \mathrm{~s} / \mathrm{d} 1+020$ & 58 & Good \\
\hline \multicolumn{2}{l}{ Nilai rata-rata PCI Segmen II } & $\mathbf{4 7 , 5}$ & Fair \\
\hline
\end{tabular}

Dari tabel 2 diperoleh nilai $P C I$ rata rata pada segmen I (sta.0+000 s/d 0+360) sebesar 50,6 dan Segmen II (sta.0+420 s/d $1+040$ ) sebesar 47,5 dengan rata-rata kedua segmen sebesar 49,05 dengan kondisi sedang (fair). Dengan nilai terendah (very poor) pada seksi 14 sebesar 18, dan nilai tertinggi (very good) pada seksi 15 sebesar 79 .

Dapat dilihat bahwa nilai $P C I$ yang diteliti pada segmen I sebesar 50,6 dengan katergori fair dan nilai PCI bagian kedua sebesar 47,5 dengan kategori fair, sehingga nilai rerata $P C I$ pada kedua segmen sebesar 49,05 dengan kategori fair yang berarti kondisi jalan pada ruas jalan Sako Baru mengalami kerusakan yang cukup parah sehingga perlu dilakukan perbaikan

Rekapitulasi persentase rating nilai $P C I$ pada ruas jalan Sako Baru dapat dilihat pada Tabel 3 berikut.

\section{Tabel 3. Rekapitulasi Persentase Kualitas} Perkerasan

\begin{tabular}{lcc}
\hline \multicolumn{1}{c}{$\begin{array}{c}\text { Kualitas } \\
\text { Perkerasan }\end{array}$} & $\begin{array}{c}\text { Jumlah } \\
\text { Seksi }\end{array}$ & $\begin{array}{c}\text { Persentase } \\
\mathbf{\%}\end{array}$ \\
\hline Very Good & 1 & 6,25 \\
Good & 5 & 31,3 \\
Fair & 6 & 37,5 \\
Poor & 3 & 18,8 \\
Very Poor & 1 & 6,25 \\
\hline \multicolumn{1}{c}{ Jumlah } & $\mathbf{1 6}$ & $\mathbf{1 0 0}$ \\
\hline
\end{tabular}

Nilai persentase jenis kerusakan atau Total Density dari ruas jalan Sako Baru terbesar adalah retak kulit buaya sebesar 2,591\%. Sedangkan Density terendah terjadi pada kerusakan jalur bahu turun sebesar $0,017 \%$ yang selengkapnya dapat dilihat pada Tabel 4 berikut ini.
Tabel 4. Rekapitulasi Persentase Jenis dan Tingkat Kerusakan

\begin{tabular}{|c|c|c|c|}
\hline $\begin{array}{c}\text { Jenis } \\
\text { Kerusakan }\end{array}$ & $\begin{array}{c}\text { Luas Seluruh } \\
\text { Seksi } \\
\left(\mathbf{f t}^{2}\right) \\
\end{array}$ & $\begin{array}{c}\text { Jenis } \\
\text { Kerusakan }\end{array}$ & $\begin{array}{c}\text { Total } \\
\text { Density } \\
(\%)\end{array}$ \\
\hline $\begin{array}{l}\text { (1) Retak Kulit } \\
\text { Buaya }\end{array}$ & & 1525,86 & 2,591 \\
\hline (6).Amblas & & 157,46 & 0,267 \\
\hline (7) Retak & $\begin{array}{l}\text { Lebar } 5,7 \mathrm{~m} \\
=18,7 \mathrm{ft}\end{array}$ & 11,4848 & 0,019 \\
\hline $\begin{array}{c}\text { pinggir } \\
\text { (9) Jalur Bahu }\end{array}$ & $\begin{array}{l}\text { Panjang }=960 \\
\mathrm{~m}=3148,8 \mathrm{ft}\end{array}$ & 9,84 & 0,017 \\
\hline $\begin{array}{c}\text { Turun } \\
\text { (11)Tambalan } \\
\text { dan Galian }\end{array}$ & $\begin{array}{l}\text { Luas s }=18,7 \mathrm{x} \\
3148,8= \\
58.882,56 \mathrm{ft}\end{array}$ & 792,29 & 1,346 \\
\hline (13)Lubang & & 111,53 & 0,189 \\
\hline $\begin{array}{l}\text { (19) Pelapesan } \\
\text { Butiran }\end{array}$ & & 222,26 & 0,377 \\
\hline
\end{tabular}

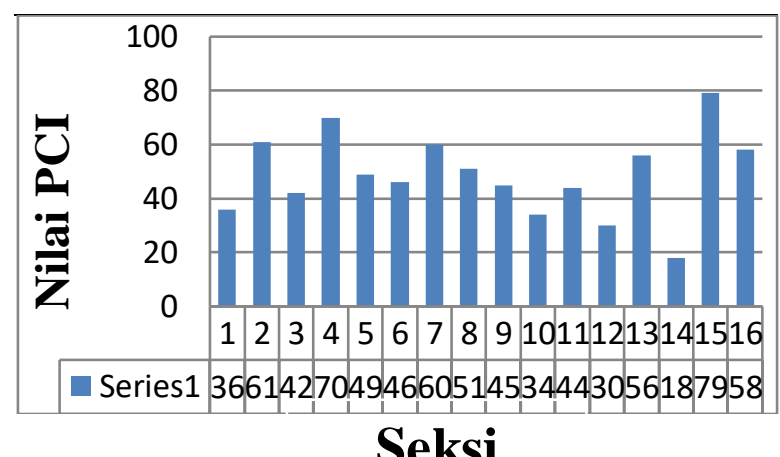

Gambar 6. Grafik Hubungan Kerusakan Jalan Sako Baru Antara Stasiun dengan Nilai PCI

\subsection{Pembahasan dan Analisa}

Persentase nilai kerusakan dalam perhitungan $P C I$ pada setiap rating adalah very good sebanyak 1 segmen sebesar 6,25\%, good sebesar $31,3 \%$ dengan 5 jumlah segmen, fair sebesar 37,5\% dengan 6 jumlah segmen, poor sebesar 18,8\% dengan 3 jumlah segmen, dan very poor sebesar 6,25\% sebanyak 1 segme. Dari persentase tersebut, terlihat bahwa rating fair mendominasi tingkat kerusakan $P C I$ dengan jumlah sebanyak 6 segmen.

Menurut acuan dalam penelitian ini, terdapat 19 jenis kerusakan jalan, akan tetapi, hanya ada 7 macam kerusakan jalan yang terjadi pada ruas jalan Sako Baru, diantaranya adalah alligator cracking sebesar 2,591\%, depressions sebesar 0,267\%, edge cracking sebesar 0,019\%, shoulder drop off sebesar $0,017 \%$, patching \& utillity cut patch sebesar $1,346 \%$, potholes sebesar $0,189 \%$, dan 
weathering/ravelling sebesar $0,377 \%$.

Secara umum, perhitungan penelitian kerusakan jalan dengan $P C I$ ini menunjukan bahwa kondisi kualitas perkerasan lentur pada ruas jalan Sako Baru Kecamatan Sako Palembang adalah sedang (fair) dengan kerusakan maksimum yang dicapai adalah 18 dengan kategori very poor dan tertinggi 79 dengan kategori very good. Apabila ditinjau dari perhitungan $P C I$ di setiap seksi, bahwa perkerasan membutuhkan perbaikan struktural dengan cara overlay.

\section{KESIMPULAN}

Dari hasil penelitian ini dapat disimpulkan sebagai berikut :

1. Jenis-jenis dan tipe kerusakan yang banyak dijumpai di lapangan yaitu aligator cracking $2,591 \%$, patching $1,346 \%$, dan weathering ravelling $0,377 \%$ juga ada beberapa bagian yang mengalami kerusakan depression $0,267 \%$, edge cracking $0,019 \%$, shoulder drop off $0,017 \%$ dan potholes $0,189 \%$.

2. Nilai $P C I$ rata-rata sta $0+000$ s.d sta $0+360$ sebesar 50,6 , untuk sta $0+420$ s.d sta $1+020$ sebesar 47,5

3. Nilai kinerja perkerasan secara visual $P C I$ didapatkan hasil nilai terendah berada pada seksi 14 sebesar 18 dengan kategori very poor sedangkan rating tertinggi berada pada seksi 15 sebesar 79 dengan kondisi very good.

4. Kerusakan yang didominasi oleh retakan tersebut terjadi karena aspal telah mengalami lelah (fatique) sehingga tidak mampu lagi menahan beban kendaraan yang melewatinya.

5. Perkerasan mengalami kerusakan pada strukturnya, sehingga diperlukan perbaikan struktural (overlay) agar dapat melayani lalu lintas dengan baik.

\section{DAFTAR PUSTAKA}

[1] Wenda Pradita, Zainal Aqli, Sutan P Silitonga 2018, Evaluasi Tingkat Kerusakan Jalan Dengan Metode Pavement Condition Index (PCI) Untuk Menunjang Pengambilan Keputusan (Studi Kasus Ruas Jalan Nasional Kabupaten Pulang Pisau Provinsi Kalimantan Tengah), Jurnal Proteksi (Proyeksi Teknik Sipil) Volume 4, Nomer 1, januari 2018 Jurusan/Prodi Teknik Sipil, Fakultas Teknik Universitas Palangka Raya hal 4041

[2] Hardiyatmo,C.,H. 2015. Pemeliharaan Jalan Raya. $2^{\text {nd }}$ ed. Gadjah Mada University Press. Yogyakarta

[3] FAA, 1982. Guidelines and Procedures for Maintenance of Airport Pavement. Wasington DC : Us Departement of Transportation.

[4] Shahin, M.Y. 1996. Pavement Management For Airport, Roads, and Parking Lots. New York : Chapman \& Hall.

[5] Susanti Djalante, 2011. Evaluasi Kondisi dan Kerusakan Perkerasan Lentur di Beberapa Ruas jalan Kota Kendari. Majalah Ilmiah MEKTEK Tahun XIII No. 1, Januari 2011, hal 5. 